\title{
Complementary feeding: inappropriate practices in infants
}

\author{
MICHELLE CAVALCANTE CAETANO ${ }^{1}$, THAÍS TOBARUELA ORTIZ ORTIZ ${ }^{1}$, \\ SIMONE GUERRA LOPES DA SILVA ${ }^{1}$, FABÍOLA ISABEL SUANO DE SOUZA², \\ ROSELI OSELKA SACCARDO SARNI ${ }^{3}$
}

1. Mestranda, Ciências Aplicadas à Pediatria, Universidade Federal de São Paulo (UNIFESP), São Paulo, SP, Brazil.

2. Mestre, Ciências Aplicadas à Pediatria, UNIFESP, São Paulo, SP, Brazil. Professora colaboradora, Faculdade de Medicina do $A B C$ (FMABC), Santo André, SP, Brazil.

3. Doutora, Medicina, UNIFESP, São Paulo, SP, Brazil. Professora assistente, FMABC, Santo André, SP, Brazil.

\begin{abstract}
Objective: To assess feeding practices and dietary intake of healthy infants in three Brazilian municipalities. Methods: By means of a prospective study, we analyzed the food record of 7 consecutive days of an intentional sample (quota and weighted sampling) of 179 healthy infants, aged between 4 and 12 months, from the municipalities of Curitiba, São Paulo, and Recife, who were not being exclusively breastfed. Mothers received oral and written information provided by a nutritionist with the purpose of standardizing the feeding data. The computer program NutWin was used to calculate the dietary intake. Results: The median of the infants' age was 6.8 months (4.0-12.6 months). We found that $50.3 \%$ of the infants were no longer being exclusively breastfed. Of these, 12.0 and $6.7 \%$ among the infants younger and older than 6 months, respectively, were fed with infant formulae instead of breast milk. Therefore, most infants received whole cow's milk. Infant formula dilution was correct in only 23.8 and $34.7 \%$ of the infants younger and older than 6 months old, respectively. With regards to complementary feeding, we found that the median age was 4 months for its introduction and 5.5 months for the introduction of family diet. There was high quantitative inappropriateness of micronutrient intake for infants between 6 and 12 months old who were not exclusively breastfed, mainly in terms of zinc (75\%) and iron (45\%). Conclusion: The present study showed a high frequency of inappropriate feeding practices and dietary intake in very young infants. These practices may lead to an increased risk of development of chronic diseases in the future.

(Key words: Dietary behavior, disease prevention, infant's nutritional disorders, infant care).

J Pediatr (Rio J) 2010; 86 (3): 196-201
\end{abstract}

\section{ESTE TRABAJO LO PUEDE ENCONTRAR EN EXTENSO EN WWW.SciELO.ORG}

This study was conducted at the School of Medicine of Fundação do ABC (FMABC), Santo André, SP, Brazil. Financial support: Nestlé Nutrition Institute.

No conflicts of interest declared concerning the publication of this article.

Correspondencia a:

Roseli Oselka Saccardo Sarni

E-mail: rssarni@uol.com.br 